\title{
Research on Mathematical Core Competency Cultivation Based on Polya Problem Solving Table
}

\author{
Chao Yang: School of Mathematical Sciences, University of Jinan, Jinan, Shandong 250022, P R China. \\ -Zhenlai Han: School of Mathematical Sciences, University of Jinan, Jinan, Shandong 250022, P R China. \\ Shurong Sun: School of Mathematical Sciences, University of Jinan, Jinan, Shandong 250022, P R China.
}

\begin{abstract}
The core competency of mathematics has always been a hot issue in the education field. The ability to solve problems in mathematics is also an indispensable ability to learn mathematics problem solving. The Polya problem solving table has an important guiding role for mathematics problem solving. Simplify the Polya problem-solving form to make it more suitable for high school teaching. Through the Polya problem-solving table, the cultivation of mathematical core competency is integrated into the process of mathematical problem-solving for our mathematics teaching and promote the development of students' mathematical core competency.
\end{abstract}

Key words: Mathematical core competency, Polya Problem Solving Table, Mathematical problem solving.

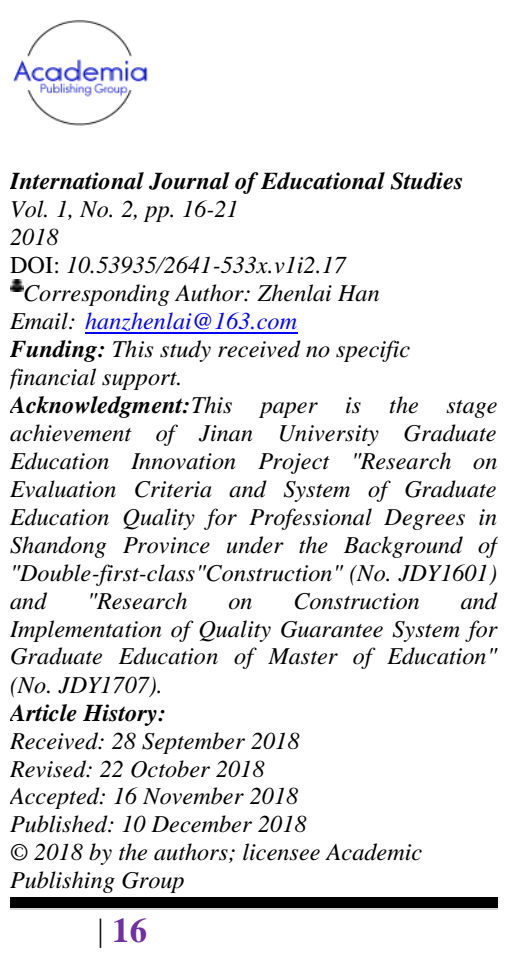

\section{Introduction}

Core competency has been a hot topic in the education field in recent years. For exa-mple, in the "21st Century Skills" released by the United States in 2002 (Partnership for 21st Century Skills, 2002), the OECD and EC respectively proposed a core competency framework. PISA's assessment of student competency also raises the education community's focus on core competence (OECD, 2004, European Commission, 2005). In 2014, the Ministry of Education of the People's Republic of China issued the "Opinions of the Ministry of Education on Comprehensively Deepening the Reform of Curriculum Reform and Implementing the Fundamental Tasks of Lide Shuren", requiring research and development of students' core competency system and academic quality standards, and demanding that the core competency of the discipline be highlighted. The publication of the 2016 "China Student Development Core Competency" framework and the publication of "21st Century Student Development Core Competency" further enhanced the attention of "core competency" (Lin, 2016).

In the field of mathematics education, the core competency of mathematics has also been the focus of people's discussion. The core competence of mathematics also has different names in various countries, including numeracy (UK, Canada), quantitative competency (USA), mathematical competence (Denmark, Finland, OECD). But in China, there is still no accurate translation of the core competence of mathematics (Zhang, 2017). However, because the core competency used in the "21st Century Student Development Core Competency" English is "key competency", here So we call it the "mathematical key competency" (Lin, 2016). In China, the core competency of mathematics is considered to be an organic whole consisting of six parts: mathematical abstraction, logical reasoning, mathematical modeling, visual imagination, mathematical 
operation and data analysis. These six core math competency guide the teaching of high school teachers and are the main part of the college entrance examination.

\section{Polya Problem Solving Table}

American mathematician Polya is a famous mathematician and mathematics educator. His English version of "How to Solve it " was published in 1944 and translated into Chinese in 1948. In the 1980s, Polya's "How to Solve it" received wide attention in China and greatly promoted the cause of mathematics education in China (Dai and Han 2009).

Solving problems in mathematics learning is indispensable, and it is an important method for us to examine students' knowledge. The cultivation of core competency of mathematics makes our ultimate goal, then how to combine our core competency of mathematics with mathematical problem solving, how to cultivate students' core competency in the process of solving problems is a very valuable problem.

How to solve the problem table of Polya is suitable for mathematics learners, but after all, it is not specially written for Chinese high school mathematics learners, so in order to make it more suitable for Chinese mathematics learners, the author has carried out a certain degree of Simplification makes it easier for Chinese high school students to accept. For example, because Chinese high school students emphasize the idea of combining numbers and shapes, students should try to draw a picture in the process of understanding the topic. In addition, because the conditions in the topics of high school students in China are sufficient, the thinking on whether the conditions are sufficient in the list of problems in Polya is deleted.

\begin{tabular}{ll}
\hline Understand the & What is the unknown? What is the known data? What are the conditions? Can \\
problem & you write it? \\
& Draw a picture as much as possible? \\
& Do you have a deeper understanding of the conditions and what are the new \\
findings in combining the various conditions? & Have you seen a similar topic? Do you know a related topic? Do you know the \\
theorem that may be used? Look at the unknown! \\
Devise the plan \\
Have! Can you use the results? method? Introducing other elements? \\
No! Restate it and return to the definition! \\
Can it be simplified? Universalization Specialization? Keep some conditions? \\
Change known data or unknowns? \\
Is the known data all used? Are all the conditions used? Are all the key concepts \\
used? \\
Can you ensure that the logic is tight? Can you ensure that the calculations are \\
correct? \\
Can you test your results? (Formally, intuitively, starting from the weakest \\
place) \\
Can you derive it in different ways? \\
Can you use this method or result in other topics? \\
Can you change this topic and answer it?
\end{tabular}

International Journal of Educational Studies Vol. 1, No. 2, pp. 16-21

2018

DOI: $10.53935 / 2641-533 x . v 1 i 2.17$

"Corresponding Author: Zhenlai Han

Email:hanzhenlai@163.com

Funding: This study received no specific

financial support.

Acknowledgment:This paper is the stage

achievent of Jinan University Gradu achievement of Jinan University Graduate Education Innovation Project "Research on Evaluation Criteria and System of Graduate Education Quality for Professional Degrees in
Shandong Province under the Background of Shandong Province under the Background of
"Double-first-class"Construction" (No. JDY1601) and "Research on Construction and Implementation of Quality Guarantee System for Graduate Education of Master of Education" (No. JDY1707).

Article History:

Received: 28 September 2018

Revised: 22 October 2018

Revised. 22 October 2018

Accepted: 16 November 2018

Published: 2018 by the authors: licensee Academic

Publishing Group

| 17

\section{Problem Analysis}

The following description will be made with reference to examples. It is known that $a, b, c$ are the opposite sides of the three inner angles $\mathrm{A}, \mathrm{B}$, and $\mathrm{C}$ of $\triangle \mathrm{ABC}$ respectively. $a=2$ and $(2+b)(\sin A-\sin B)=(c-b) \sin C$, Then the maximum area of $\triangle \mathrm{ABC}$ is

\subsection{Understand the Problem}

The stage of understanding the topic is mainly the cultivation of mathematical abstraction ability. Students with strong mathematical abstraction can abstract practical problems into mathematical problems, classify known, conditional, and unknown through topics. More importantly, they can see the hidden conditions behind the questions (such as some students can see at a glance $f(x)=\frac{\log |x|}{x}$ is an odd function). 
Mathematical abstraction ability can help students understand the topic more comprehensively, and can also develop students' mathematical abstraction ability while understanding the topic (Wei $\mathrm{Ke}$ and $\mathrm{Hu}$ Dianshun 2017). In this case, the topic information can be divided into three parts: known, conditional, and unknown to understand and understand.

\begin{tabular}{lll}
\hline \multicolumn{1}{c}{ Known } & Conditional & Unknown \\
\hline $\begin{array}{l}a, b, c \text { are the opposite } \\
\text { sides of the three inner } \\
\text { angles } \mathbf{A}, \mathbf{B}, \text { and } \mathbf{C} \text { of }\end{array}$ & $(2+b)(\sin A-\sin B)=(c-b) \sin C$ & $\begin{array}{l}\text { the maximum area } \\
\text { of } \Delta \mathbf{A B C}\end{array}$ \\
$\mathbf{\Delta \mathbf { A B C }}$ & & \\
\hline
\end{tabular}

Analysis: The first step requires only the mathematical abstraction ability of the initial level, that is, classifying all the information. We can also think that classifying information is the premise of mathematical abstraction. Polya will understand the topic into familiar topics and in-depth understanding of the topic. Indepth understanding of the topic requires careful consideration of each part of the topic, and then consider the various parts of the topic together, the most important of which is to combine the conditions for consideration. There are only two conditions in this question, so we need to combine the two conditions. After combining the two conditions, the sine theorem can be used to obtain the implicit condition " $c^{2}+b^{2}-a^{2}=b c^{\prime \prime}$. Then the cosine theorem can be used to obtain another implicit condition " $\cos A=\frac{1}{2}$ " is $\angle A=\frac{\pi}{3}$. If you understand the topic in this step, you will have an in-depth understanding of the topic, which is to abstract a deeper meaning from the information given by the topic.

\subsection{Devise the Plan}

The core of Polya's problem-solving idea is to actively mobilize the previous problem-solving ideas and problem-solving experience to serve the current topic, and to make the current topic serve the future problemsolving activities, so the success of the plan is planned. It is closely related to previous problem-solving experience and problem-solving skills. Therefore, the process of formulating the plan is on the one hand the process of cultivating students' problem-solving skills, and on the other hand, the process of cultivating students' core competency. In the planning stage, logical reasoning, mathematical modeling, visual imagination, mathematical operations and other competency can be cultivated.

Analysis: The competency of different methods is different for this topic, and the most conventional methods permeate the competency of mathematical operations and logical reasoning.

"Have you seen a similar problem? Start with an unknown!" The most important knowledge point for the $\triangle \mathrm{ABC}$ area is that the area of the triangle can be expressed as $\frac{1}{2} b c \sin A$. "Can you use them?" In the process of understanding the topic, we obtained $\angle A=\frac{\pi}{3}$ through mathematical abstraction, that is, $\sin A=\frac{\sqrt{3}}{2}$. So we

International Journal of Educational Studies Vol. 1, No. 2, pp. 16-21

2018

DOI: $10.53935 / 2641-533 x . v 1 i 2.17$

Corresponding Author: Zhenlai Han Email: hanzhenlai@163.com Funding: This study received no specific financial support.

Acknowledgment:This paper is the stage Ackiowent of Jian achievement of Jinan University Graduate Education Innovation Project Research on Evaluation Criteria and System of Graduate Education Quality for Professional Degrees in Shandong Province under the Background of "Double-first-class"Construction" (No. JDY1601) and "Research on Construction and Implementation of Quality Guarantee System for Graduate Education of Master of Education" (No. JDY1707).

Article History:

Received: 28 September 2018

Revised: 22 October 2018

Accepted: 16 Nover 2018

Accepted: 16 November 2018

Published: 10 December 2018

(C) 2018 by the aut
Publishing Group

$$
\text { | } 18
$$
have to use $\frac{1}{2} b c \sin A$, we only need to determine the range of bc. And the condition related to bc is $c^{2}+b^{2}-a^{2}=b c$, the question comes again "Can you use them?" In order to use it we substitute $a=2$ to get about $b^{2}, c^{2}, b c$ expression $b^{2}+c^{2}-b c=4$ we again use the problem in the problem-solving table "Do you know a usable theorem?" The theorem about $b^{2}, c^{2}, b c$.

We naturally think of the mean inequality, at which point we are able to determine an inequality for bc to determine the range of values for the $\mathrm{ABC}$ area. We can find the shadow of logical reasoning in almost any solution problem, which is more obvious in the proof. The logical reasoning competency makes the problemsolving process closely linked, clear and concise, and is conducive to the formulation of the solution. 


\subsection{Carry out the Plan}

The implementation phase is primarily the implementation of the proposed planning phase, ensuring that each step is correct. It is mainly the embodiment of mathematical operation competency and logical reasoning competency.

Analysis: In this question

$\because a=2,(2+b)(\sin A-\sin B)=(c-b) \sin C$,

$\therefore(a+b)(a-b)=(c-b) c \Rightarrow c^{2}+b^{2}-a^{2}=b c \Rightarrow \cos A=\frac{1}{2} \Rightarrow A=\frac{\pi}{3}$,

$\therefore \triangle \mathrm{ABC}$ area $\mathrm{S}=\frac{1}{2} b c \sin A=\frac{\sqrt{3}}{4} b c$.

$\because c^{2}+b^{2}-a^{2}=b c$,

$\therefore b^{2}+c^{2}-b c=4 \Rightarrow b c \leq 4 \Rightarrow S=\frac{\sqrt{3}}{4} b c \leq \sqrt{3}$.

That is, the maximum area of $\triangle \mathrm{ABC}$ is $\sqrt{3}$.

\subsection{Look Back}

Compared with the other three stages, the review stage is the most important for the core competency training of mathematics. Because the review phase can maximize the benefits of doing the problem, such as "Can you derive in different ways in the review phase?" can help us think more ways to cultivate our core mathematics in all aspects. "Can you use this method or result in other topics?" It is also possible to have each question serve the future problem-solving activities, so that learners can think about the breadth of each type of mathematical core competency application.

For the purposes of this question, we think in terms of the questions in the table. "Can you test your results?" Using logical reasoning to test the process of the topic, I found no problem. "Can you derive it in different ways?" Of course! When we have two conditions $a=2$ and $\angle A=\frac{\pi}{3}$, we can solve the problem through intuitive imagination competency and mathematical modeling competency.
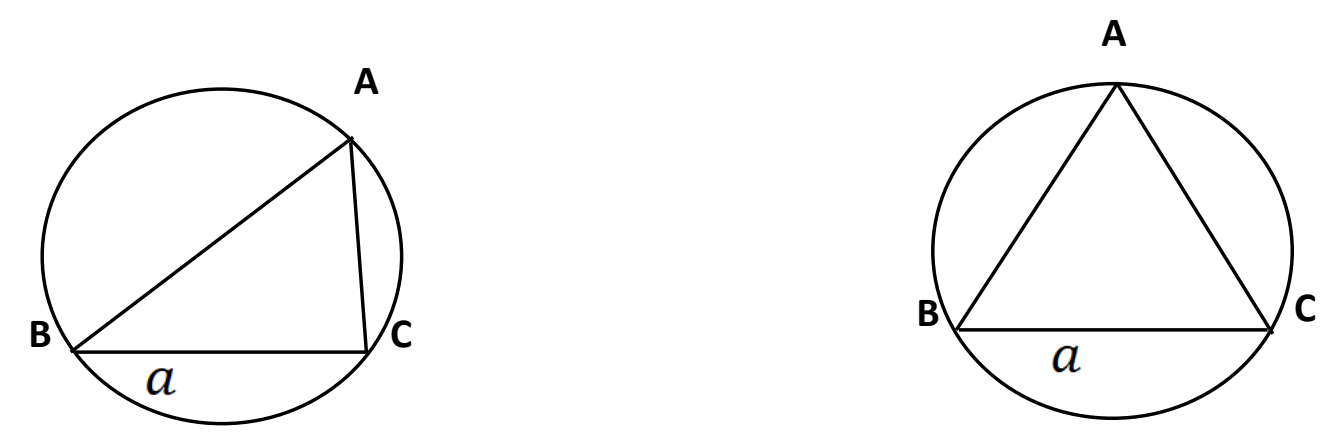

We fixed the points $\mathrm{B}$ and $\mathrm{C}$ of the triangle on the circle, $\mathrm{BC}=2$ and the circumferential angle of the arc $\mathrm{BC}$ is $\frac{\pi}{3}$. At this point, point A moves on the superior arc BC. During the motion, we get a triangle with a fixed $\mathrm{BC}$ and a high variation. When $\mathrm{AB}=\mathrm{BC}$, the height of the triangle is the largest, and the area of the triangle is at most $\sqrt{3}$. "Can you use this method and result in other topics?", reviewing the whole process, paying attention to the use of mathematical abstraction in the process of understanding the topic to deeply understand

Vol. 1, No. 2, pp. 16-21

2018

DOI: $10.53935 / 2641-533 x, v 1 i 2.17$

Corresponding Author: Zhenlai Han

Email: hanzhenlai@163.com

financial support.

Acknowledgment:This paper is the stage achievement of Jinan University Graduate Evaluation Critation Project Research on Education Quality or Prof Systen of Gerides "Double firstevince under the Background of and Implentearch on Construction Implementation of Quality Guarantee System for Graduate Education of Master of Education (No. JDY1707).

Received: 28 September 2018

Revised: 22 October 2018

Accepted: 16 November 2018

Published: 10 December 2018

(c) 2018 by the authors; licensee Academic

Publishing Group

| 19 
the topic, paying attention to the process of planning and implementing the plan. Logical reasoning ensures that every step is correct. In the process of reviewing, try various problem solving methods and comprehensively apply various core competency. In terms of methods, we pay attention to the classification of topic information, focus on deep understanding of topics, and pay attention to the transformation and combination of conditions. Specifically, the area of the triangle is equal to the product of the sides of the triangle of $\frac{1}{2}$ and the sine of the angle. For the sine of the triangle and the sine of the angle, the sine theorem is taken into account, and the edge of the triangle appears in the title. The relationship is considered by considering the cosine theorem of the triangle and transforming the edge relationship. "Can you change this question and then answer it?" We can change the maximum value of " $b+c$ " for this topic, which makes our thinking more divergent and more knowledge, so that we have more opportunities to think through development our mathematical key competency.

\section{The Cultivation of Mathematics Core Competency in the Problem-Solving Teaching}

The Polya Problem Solving Table divides the problem solving into four parts, which are the four stages of understanding the topic, drafting the plan, implementing the plan, and reviewing. The integration of mathematical core competency in these four stages can make the teacher's purpose more clear.

\subsection{Understand the Problem Stage}

Mathematical abstraction refers to the acquisition of mathematical research objects through the abstraction of quantitative relations and spatial forms. It mainly includes: abstracting the relationship between mathematical concepts and concepts from the relationship between quantity and quantity, the relationship between graphics and graphics, and extracting general laws and structures from the specific background of objects. The cultivation of mathematical abstract competency mainly occurs in the stage of understanding the subject. To enable students to abstract the general rules and structures, students need to have a certain knowledge base. Therefore, the premise of cultivating mathematical abstraction is to pay attention to concept teaching. Secondly, to improve students' ability to think deeply, in order to explore the hidden conditions of the topic, and further abstract the general law and structure. Finally, it is necessary to cultivate students' divergent thinking, to link conditions with the knowledge in the mind, and to abstract deeper laws and structures.

\subsection{Devise the Plan Stage}

In the planning stage, a variety of mathematical core competency should be cultivated, but the focus of different types of questions is different. For example, the proof question emphasizes logical reasoning, the geometric question emphasizes intuitive resemblance, the function title emphasizes mathematical modeling, and the probabilistic question emphasizes data analysis. Therefore, high school teachers should understand the core of mathematics to be examined in each topic, and develop a certain core competency of students with a purpose in explaining each topic, so as to effectively implement the cultivation of core competency to solve problems. Go in teaching.

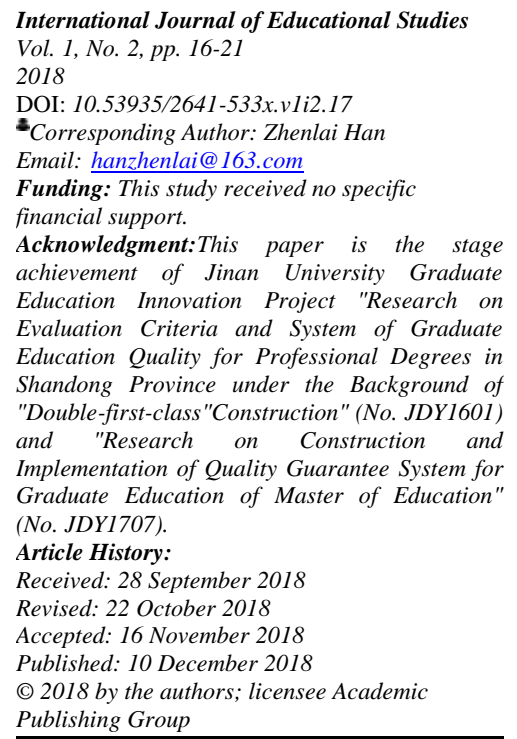

\subsection{Carry out the Plan Stage}

The execution planning phase focuses on the investigation of mathematical operations and the rigor of logical reasoning. The execution planning phase is a key step to ensure the correct rate of problem solving. Every step emphasized by the Polya Problem Solving Table during the implementation planning phase is correct, which is part of the mathematical competency and logical reasoning competency. The training strategy in the implementation planning phase is to ensure the logic is strict as a whole, and the operation is guaranteed to be correct in the steps.

\subsection{Look Back Stage}

The review stage can be said to be the most important of the four stages. You can master more problem solving methods by thinking about multiple problem solving methods and changing topics, and cultivate more core competency. In the previous question, the conventional method emphasizes the mathematical competency of logical reasoning, and in the second method emphasizes the mathematical competency of 
intuitive imagination and mathematical modeling. Then through the change of the subject to master more problem-solving methods and problem-solving skills, in this process to cultivate more mathematical core competency. If the proposed planning phase is targeted at the cultivation of six core mathematics nuances, then the retrospective phase is the overall cultivation of the core competency of mathematics. Therefore, in the process of solving the problem teaching, the review process is emphasized, the exploration of different methods is emphasized, the change of the subject is emphasized, and the cultivation of the core competency of mathematics can be integrated into the process of solving the problem to the maximum extent.

\section{Conclusion}

The core competency of mathematics is inherently hidden in the process of solving mathematics problems. Educators should discover the core nuances of mathematics to be examined in each question to carry out targeted problem-solving teaching. In the stage of understanding the topic, emphasis is placed on excavating the conditions of the subject and cultivating mathematical abstract competency. In the preparation of the planning stage, determine the core competency of mathematics to be cultivated for each topic, and carry out targeted teaching. In the implementation planning stage, the accuracy of mathematical operations and the rigor of logical reasoning are cultivated to ensure the correct rate of problem solving. In the retrospective stage, divergent thinking, changing topics, and maximizing the cultivation of mathematical core competency through practice.

\section{References}

Partnership for 21st Century Skills. (2002). Framework for 21st Century Learning [EB/OL]. Available from http://www.p21.org/overview/skills-framework, 2002-05-15/2016-10-22.

OECD. (2004). Completing the Foundation for Lifelong Learning: An OECD Survey of Upper Secondary Schools. OECD: Paris.

European Commission. (2005). Lifelong Learning and Key Competence for All: Vital Contribution to Prosperity and Social Cohesion $2005 \quad$ [EB/OL]. Available from http://europa.eu.int/comm/education/policies/2010et_2010_fr.html, 2008-01-16/2016-10-22. [Accessed 22 Oct 2016].

Lin Chongde. (2016). Core Competence of Student Development in the 21st Century. Beijing: Beijing Normal University Press, 2016.

Zhang Qiaoping. (2017). Mathematical Competency in Mathematics Education in Western Countries: Comparison and Prospect. Global Education Outlook,46(03): 29-44.

Dai Qin \& Han Bin. (2009). To commemorate the 60th anniversary of the Chinese version of Polya's How to Solve the Problem. Journal of Inner Mongolia Normal University (Natural Science Chinese Edition), 38(05): 599-603.

Wei Ke \& Hu Dianshun. (2017). Problem-solving teaching from the perspective of "mathematical core literacy" - from the perspective of Polia's problem-solving thought. Mathematics in Secondary Schools, 08: 95-97.

International Journal of Educational Studies Vol. 1, No. 2, pp. 16-21

2018

DOI: $10.53935 / 2641-533 x . v 1 i 2.17$

Corresponding Author: Zhenlai Han

Email: hanzhenlai@163.com

Funding: This study received no specific

financial support.

Acknowledgment:This paper is the stage

Acknowledgment: This papor is the stage

achievement of Jinan University Graduate

Education Innovation Project Research on

Evaluation Criteria and System of Graduate

Education Quality for Professional Degrees in Shandong Province under the Background of "Double-first-class"Construction" (No. JDY1601) and "Research on Construction and Implementation of Quality Guarantee System for Graduate Education of Master of Education" (No. JDY1707).

Article History:

Received: 28 September 2018

Revised: 22 October 2018

Accepted: 16 November 2018

Published: 10 December 2018

(C) 2018 by the auth
Publishing Group

$$
\text { | } 21
$$

